\title{
20 lecciones que aprendí mientras vivimos confinados
}

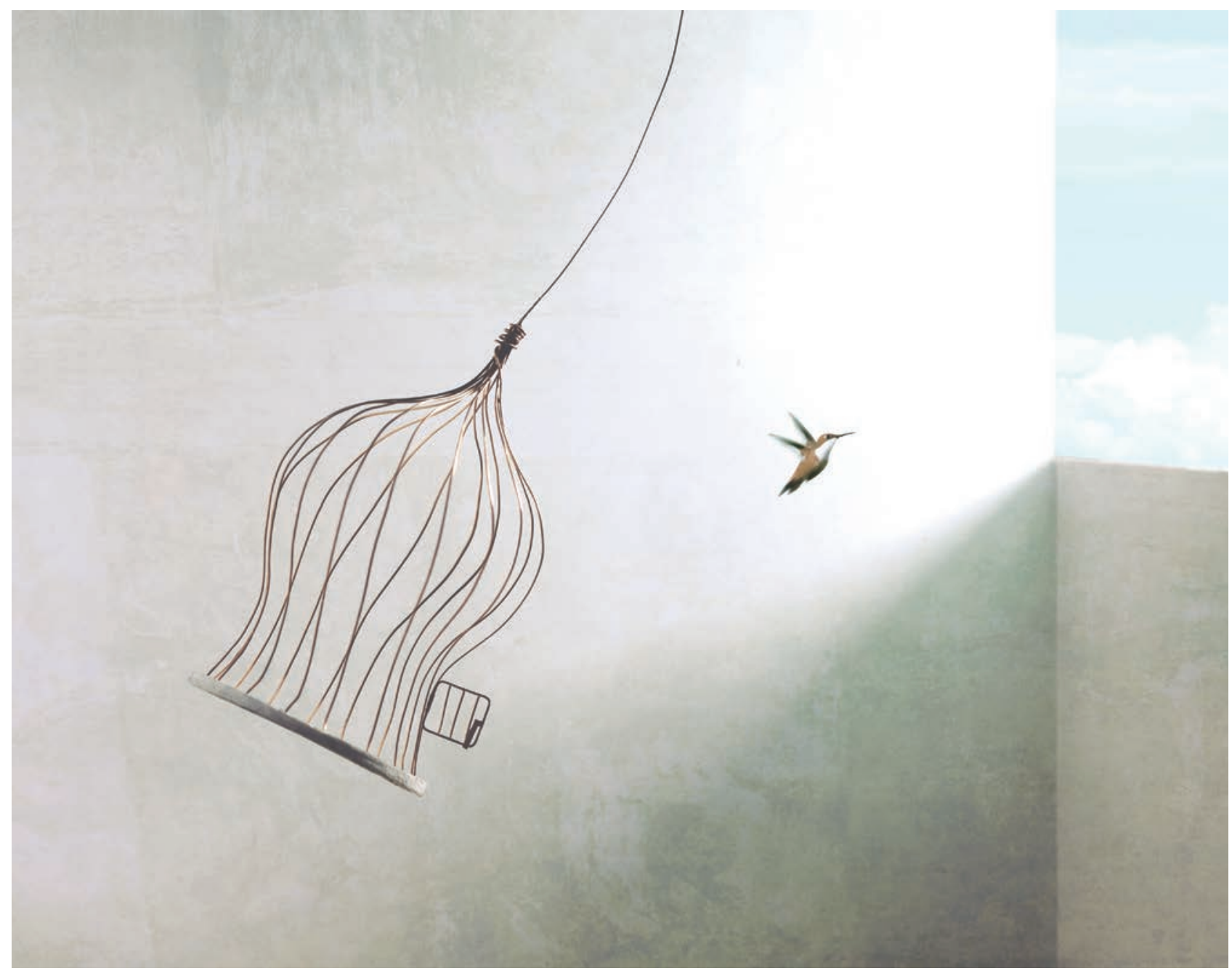

Hace sesenta años, Harper Lee publicó Matar a un ruiseñor donde narra su mirada cálida de niña de diez años hacia su familia y conciudadanos en una pequeña población de Alabama. En esas páginas, que alcanzaron pronto un notable éxito, se describe con claridad la pérdida de la inocencia de unos niños en mitad de un mundo de honestidad e injusticias, de ternura y prejuicios sociales, de igualdad y desigualdad. 

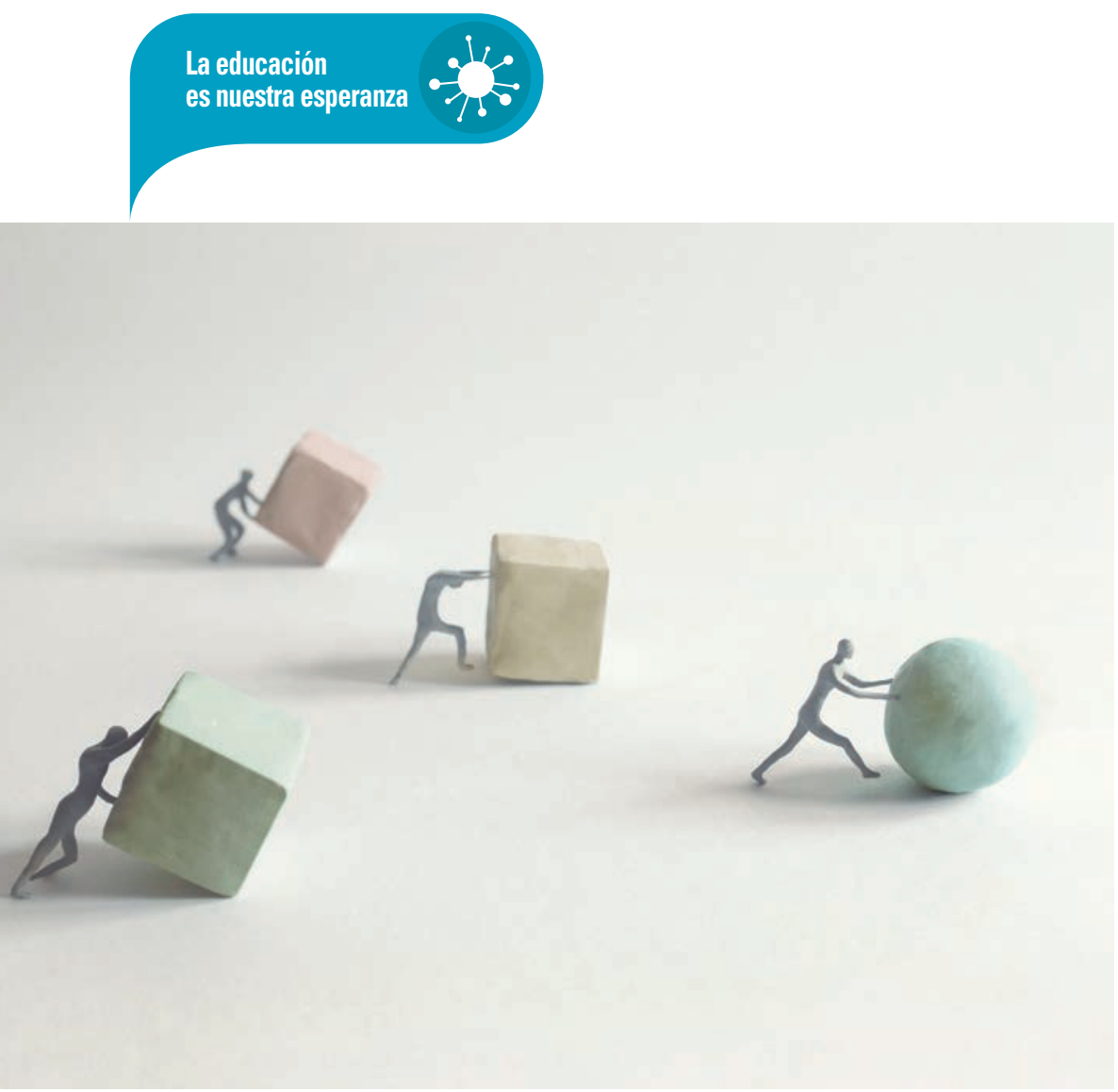

Estos meses hemos estado confinados todos en unos pocos metros, en un pequeño universo, donde, con unas pocas personas, nuestros menores han perdido su inocencia sobre cierto mundo "de celofán" en el que vivían, como en el libro. Atticus Finch, el padre, abogado comprometido con las personas de color, dialoga como un verdadero maestro varias veces con su hija Scout para irle explicando ese mundo cambiante. Estos meses hemos librado una de las batallas épicas más singulares: el estar encerrados con muy pocas personas. Los recuerdos de esta historia van a depender mucho de las lecciones aprendidas en este confinamiento en que muchos padres han sido padres y maestros a la hora de explicar este drama. Esbozaremos algunas.

\section{Desigualdad}

Es muy distinto afrontar este reto del coronavirus en una casa con jardín o terraza que sin ellos, en una casa de más de cien metros que de cincuenta, en una familia numerosa con abuelos y alguna tía que una persona sola, con alguien enfermo y confinado en una habitación que todos sanos, con trabajo que sin trabajo. El $70 \%$ de los infectados en Chicago son afroamericanos o latinos. Las desigualdades en educación, ingresos, vivienda o nutrición influyen en las posibilidades de ser infectado y en las posibilidades de cu- ración. En este confinamiento y en el confinamiento de la vida no todos jugamos con las mismas cartas. El coronavirus ha sacado a relucir desigualdades ocultas y va a crear nuevas desigualdades. Muchos perderán o han perdido su empleo y otros simplemente han tenido que trabajar desde casa, muchos tendrán jornadas extenuantes mientras otros seguirán con jornadas de 8 a 3.

\section{La muerte y la enfermedad grave}

Esta pandemia ha sido un viaje al corazón del dolor de los seres humanos. Ha desaparecido nuestra sensación de omnipotencia. Todos nos sentimos más frágiles. Un virus microscópico puede provocarnos la muerte. La muerte de miles de personas es algo que no tiene contrapeso, ni medida. Una muerte de un abuelo, de un padre, de un amigo es algo irrecuperable, irremplazable. Las antiguas culturas tenían rituales y creencias para afrontar la muerte. Hoy hemos abandonado en Europa nuestras creencias trascendentes y confiamos en una ciencia y una técnica que no siempre nos salvan o que no salvan a todos. Este virus plantea nuestra impotencia para afrontar la muerte. Ocultamos los féretros, los números, las lágrimas. La reprimimos cuando está siempre al lado.

\section{Emociones}

En estos tiempos intensos de enfermedad, muerte, paro e incertidumbre es bueno expresar y dialogar sobre nuestros sentimientos con quienes queremos por teléfono, videollamada, escribiendo una carta, un diario. Estamos conectados y las emociones de los otros nos afectan. Las emociones se transmiten, se comparten: tristeza contenida, negación, ira y enfado, culpabilización, impotencia, miedo. Las emociones no hay que cortarlas, eliminarlas, reprimirlas, negarlas. Pero tampoco hay que dejarse arrastrar, avasallar, devorar, inundar por ellas. En estos meses de coronavirus y confinamiento, es esencial aprender a gestionar nuestras emociones para que ni nos bloqueen, ni nos inunden. Necesitamos alguna protección ante tanta exposición, 
algún filtro o estrategia para atravesar el malestar y no contagiar con nuestro dolor a los que nos rodean.

\section{Pérdidas y despedidas}

En estos meses nos hemos enfrentado a pérdidas. La más importante es la de las personas, pero también ha habido otras pérdidas: la salud, el trabajo, la estabilidad, la libertad de movimiento, la posibilidad de abrazarse, los ritmos de vida, la posibilidad de estar con los amigos, etc. La pérdida nos remite al vacío dejado. Cualquier pérdida nos provoca tristeza y desolación, a menudo en diferentes grados. Afrontar las diferentes pérdidas, trabajarse por dentro, nos ayuda a fortalecernos ante las adversidades. Estos meses también han sido un aprendizaje para darse cuenta de la importancia de las despedidas. Si ha habido algo verdaderamente trágico en esta epidemia han sido las miles de personas que han muerto solas, sin compañía. En la vida hay que aprender a valorar las despedidas, a decir te quiero, perdonar o dar gracias cuando llega el fin. Para afrontar estas pérdidas y despedidas hondas, siempre han ayudado los símbolos, las imágenes, los cuentos, la poesía, las creencias para explicar lo inexplicable, para enfrentar lo que nos supera. Una foto, una vela, una estrella, una oración.

\section{Memoria y agradecimiento}

La aceptación de la realidad sin negación, sin sublimaciones, sin racionalizaciones excesivas es un signo de madurez. El dolor y el sufrimiento por alguien es la otra cara del amor y el cariño. Sufrimos por quienes amamos. Los que aman más, sufren más. Conviene en estos días en que estamos lejos de tantos, desenvolver no solo los recuerdos finales de nuestros difuntos y enfermos sino la vida entera de muchos que nos han enriquecido. Es hora de fotos, recuerdos, historia amplia, rememorar experiencias, aprendizajes recibidos. Con nuestros difuntos es importante pensar qué les gustaría que recordáramos, qué fue para él lo más importante, cuál fue su meta. Curiosamente la memoria está

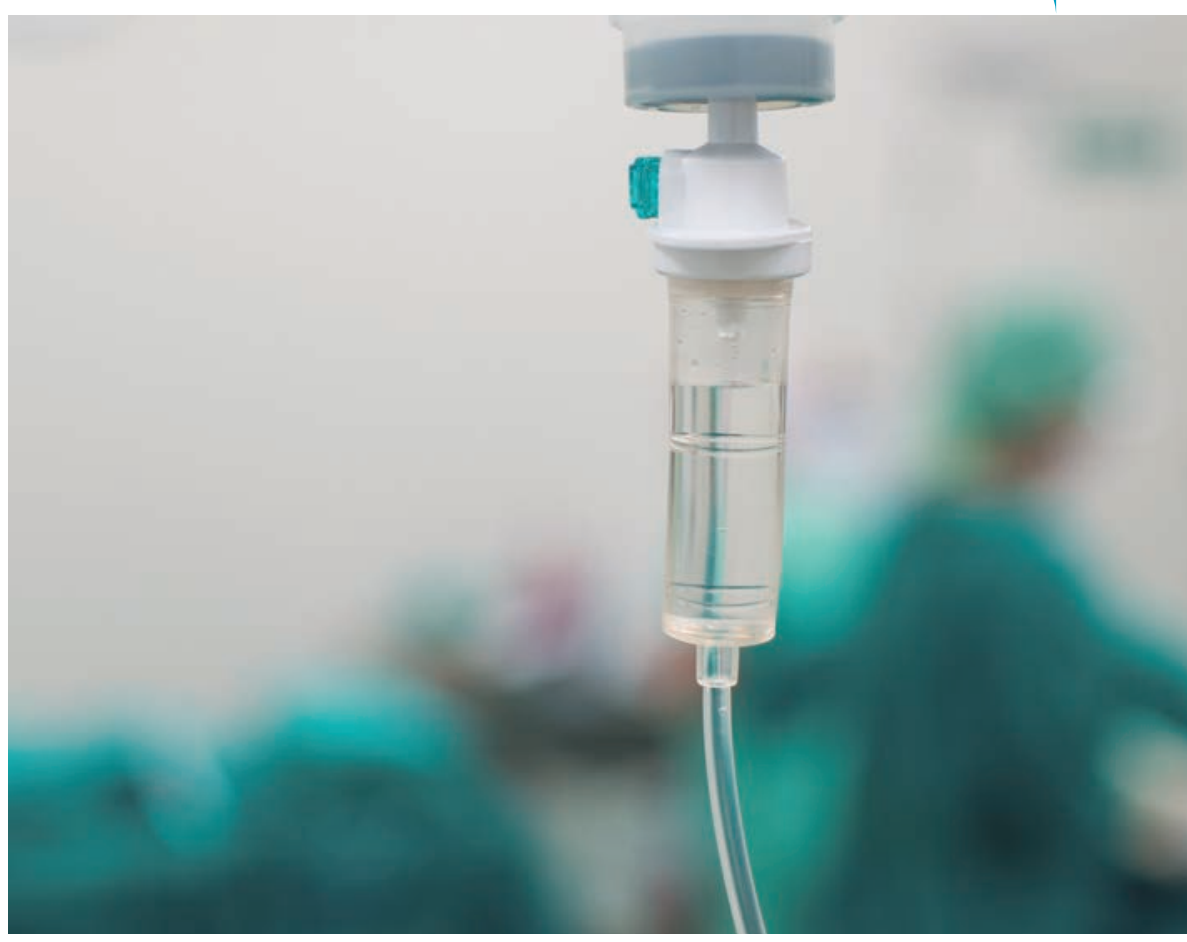

muy vinculada con el agradecimiento, con el sentir haber recibido, con el don inesperado más que con la conquista y el logro. Cultivemos la memoria y el recuerdo amable de los que nos dejaron.

\section{Orden, rutina, espejos}

En estos tiempos difíciles hemos comprendido cómo una vida ordenada, unas rutinas, unas horas de comida y ejercicio ayudan a estructurarse por dentro y evitar caer en todo tipo de excesos que no ayudan a aliviar ni el dolor ni la pena (alcohol, drogas o fármacos). Pero este tiempo de confinamiento es también un tiempo de reflejos de uno mismo, de destellos de nuestro propio ser. El coronavirus nos ha hecho mirarnos al espejo con tranquilidad, escuchar lo que hacemos y lo que querríamos hacer, el trasfondo de nuestra convivencia y de nuestra competitividad, valorar en qué estamos empeñados en la vida.

\section{Abrir diálogos}

Estos tiempos nos abren a conversaciones inimaginables, impensables. Ante lo difícil de la muerte, es bueno que los padres se sienten con sus hijos en un ambiente de tranquilidad a hablar un rato sobre la pérdida, la larga hospitalización del abuelo o del amigo, las dificultades del trabajo y dejar que los sentimientos puedan aflorar y salir. Hay que dejar es- 

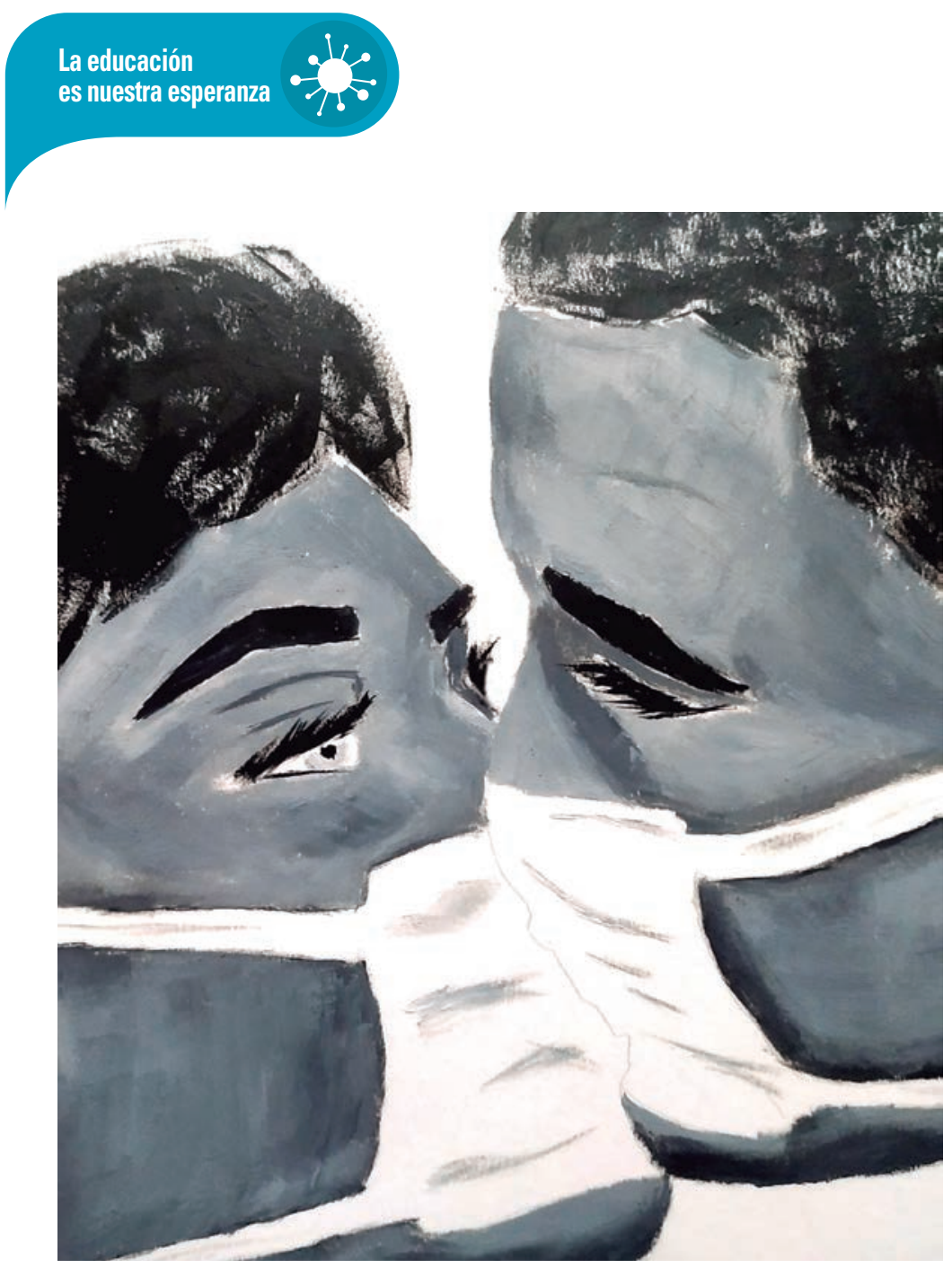

$\triangle$

Andrea

(2. ${ }^{\circ}$ Bachillerato, Centro de Formación Padre Piquer) pacios para que pregunte, para que Ilore, para que esté callado. Es bueno abrir espacios entre adultos por la noche. Expresarse los miedos, la angustia por los padres lejanos y no atendidos, por la muerte del amigo, por el no saber qué hacer es un gran aprendizaje.

\section{Tocarnos, intimidad}

El coronavirus nos ha llevado a tocar a muy pocas personas, a vivir íntimamente más de dos meses encerrados sin intimidad o con una intimidad desnuda. Este tiempo nos ha enseñado lo importante de las manos, abrazos, miradas, caricias, sentarnos juntos, comer juntos. Ha puesto en primer lugar el sentido del tacto. Los otros se han convertido en una amenaza, un peligro ante los que hay que tomar distancia. No podemos besarnos, darnos la mano, tocarnos la cara. El problema es que esta receta nos va a afectar a cómo nos saludamos y acercamos, a nuestra afectividad y sexualidad. La sexualidad no puede dejarse en un segundo plano. Muchos no han podido disfrutarla estos meses por estar demasiado pegados o aislados.

\section{Empatía}

La empatía conlleva percibir sentimientos y emociones de otros. Se es capaz de sentir el dolor o los miedos del otro. La empatía te hace salir de ti, encargarte y cuidar las necesidades del otro. Los privilegiados difícilmente se hacen cargo de los otros. Nuestro mundo ultraliberal solo se acerca al otro cuando ve una oportunidad de negocio, no para cuidar o satisfacer sus necesidades. La empatía supone comprender que todos somos iguales, que no hay personas de segunda clase. Esta epidemia ha ayudado a conectarnos más hondamente con las necesidades y los sentimientos del cercano y del lejano, del amigo y del vecino, del médico y del reponedor.

\section{Informarnos}

Es importante cómo gestionamos la información. No nos vale la sobreinformación, las ruedas de prensa largas y repetitivas, la comunicación ambigua, jugar con las cifras de los fallecidos o de los tests, las fake news, la estigmatización de razas (el "virus chino") o de mayores. Uno de los aprendizajes de este confinamiento es intentar hacernos conscientes de cómo organizamos la información, qué canales de TV o radio consultamos. La información puede extender el miedo, crear sus propios fantasmas o abrir a la sensatez y a la reflexión. Necesitamos menos influencers y grupos de Whatsapp, y ser más activos en la búsqueda de una información coherente y confiable.

\section{Pantallas}

La epidemia está incrementando aceleradamente la digitalización del mundo. Clases por Zoom, compras por Amazon, películas por Netflix, videos de YouTube para clase, etc. Cada vez somos más dependientes tecnológicamente. El consumo de internet ha subido en España un $80 \%$. Pero la digitalización difumina la realidad. Cuando nos comunicamos por pantallas, la relación se desdibuja. Las palabras pueden no remitir a verdaderos sentimientos. Desde el móvil es más fácil decir que se ama a la pareja, opinar tajantemente o despellejar al otro. Pero 
también hemos descubierto que a través de lo online nos podemos compadecer del otro, emocionarnos con su rostro, sentirlo presente. La tecnología nos puede ayudar a compartir o a dividir, nos puede humanizar o deshumanizar.

\section{Incertidumbre}

Nos debatimos entre el control totalitario y el empoderamiento de los ciudadanos en este mundo de incertidumbres. Los chinos, coreanos, taiwaneses, israelitas controlan la temperatura, las compras por internet, los paseos por la calle con cámaras, nuestro móvil, nuestros datos públicos de salud y policiales, etc. Tienen una mentalidad más proclive a la obediencia y al respeto a la autoridad. En Europa valoramos más la esfera privada y nos resistimos a que se limiten las libertades, que controlen nuestros datos o la televisión que vemos — la Sexta o la 13-. que se limite nuestro movimiento. Habermas afirma que "nunca se ha sabido tanto sobre nuestra ignorancia y sobre la compulsión a actuar y vivir bajo la incertidumbre". Es esencial cómo individual y socialmente enfrentamos las incertidumbres.

\section{Sin líderes}

Gobernantes como Trump, Bolsonaro, Netanyahu, Salvini, Johnson, Orbán no han reaccionado con altura de miras. Hoy no hay liderazgo, ni cooperación seria. Holanda y Bélgica - hacia dentro con sus mayores y hacia afuera con Europa - no están siendo muy ejemplares. Estados Unidos ha abandonado su papel de líder mundial; su retirada de fondos a la OMS o las declaraciones de Trump sobre inyecciones de lejía son actitudes de un irresponsable. Hacen falta líderes que contengan sus emociones, que marquen caminos, metas, estrategias. No abundan, pero necesitamos líderes para un Estado social que ayude ante tanto paro y empresas en quiebra.

\section{Parejas al límite}

No todos pueden aguantar, muchos están llenos de grietas psicológicas. A veces un miembro de la pareja tiene rigideces extremas, poca flexibilidad, traumas

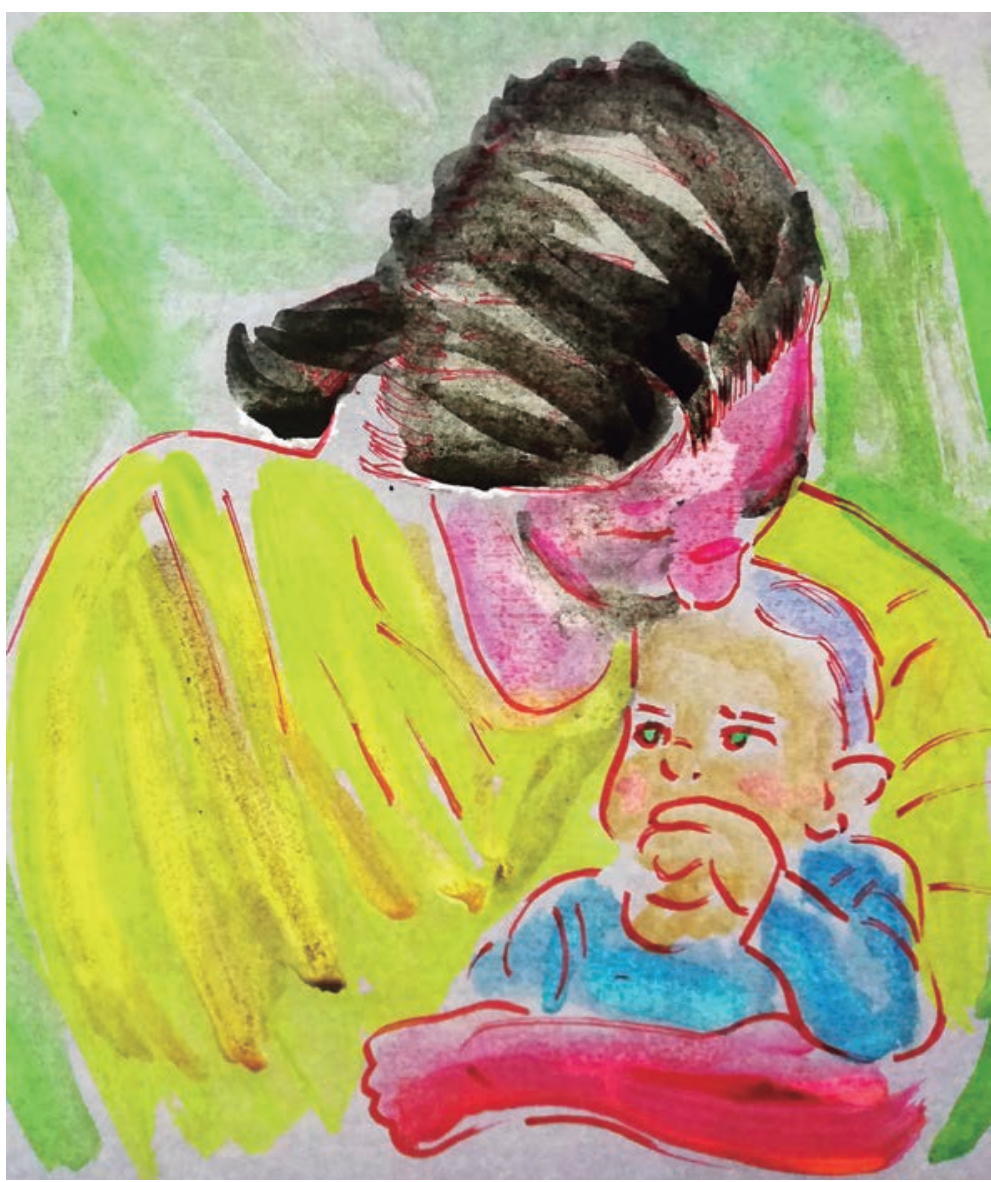

de años; en la medida que las reacciones agresivas, impulsivas, inseguras ante lo Ilustración de Juan Calvin Palomares

exterior se vuelcan también en lo interior, en la medida que hay personas al límite, esta situación puede desintegrar muchos hogares si no hay una persona que compense o pacifique. En algunos hogares, los enfrentamientos han Ilevado al divorcio. Muchas parejas, sin la ayuda de los abuelos, sin trabajo, se han encontrado desnudos y sin saber cómo actuar. Otras, se han encontrado de nuevo.

\section{Mujeres}

Las mujeres son las que están soportando más la crisis. Sobre ellas recae todavía el cuidado de mayores y menores, los trabajos más precarios y peor pagados, las jornadas más dilatadas, gran parte de la limpieza de la casa y la comida de todos. Cierto que también se están abriendo en muchos hogares nuevas formas de colaboración e incluso nuevos aprendizajes. Por eso, esta epidemia supone la necesidad de hacer justicia a las mujeres, integrar mejor los afectos y el sentimiento con la razón, reencontrar nuevas masculinidades. 


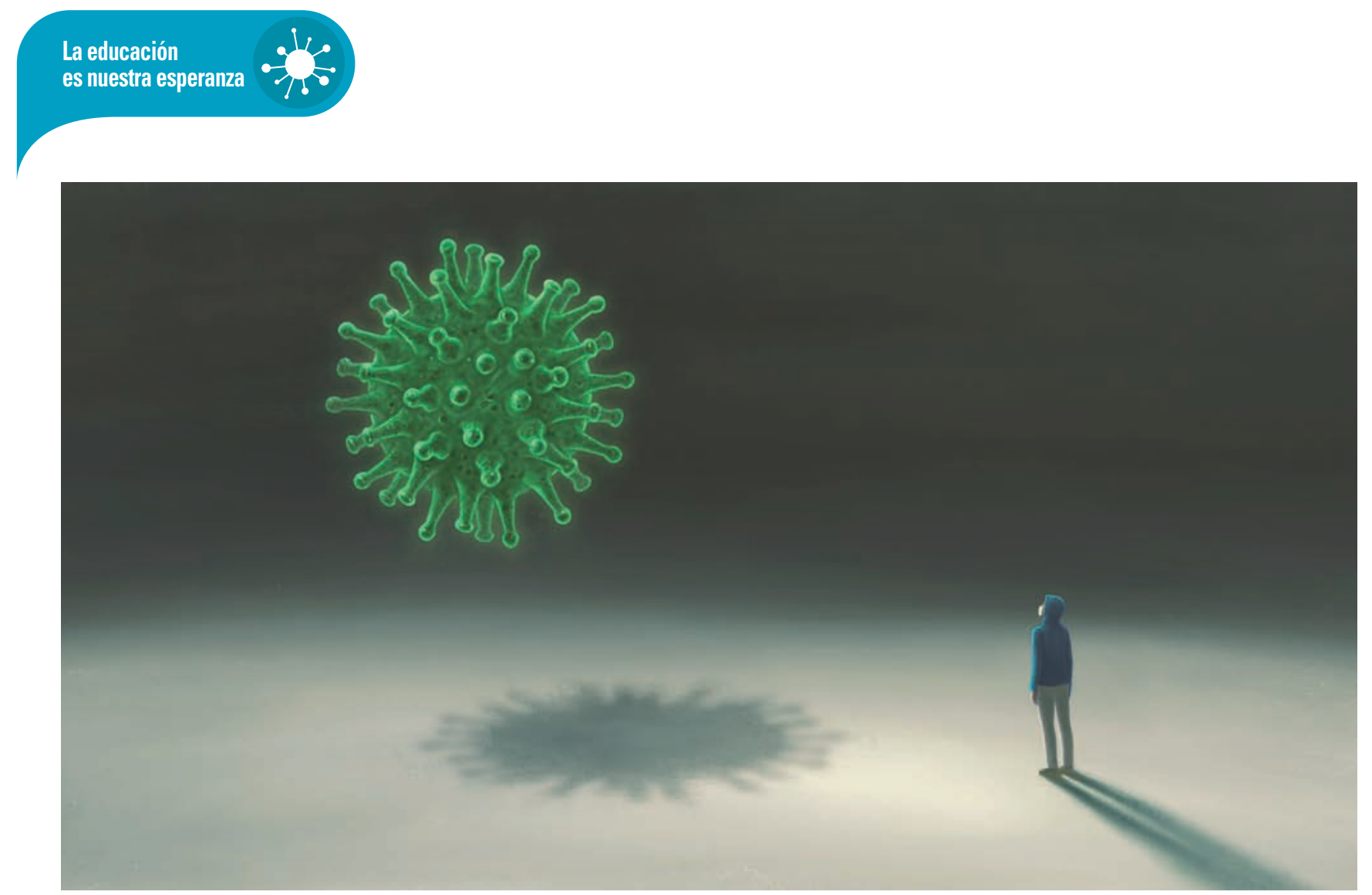

\section{Trabajo}

Se van a perder millones de trabajos, se van a debilitar muchos ya deteriorados, van a cerrar múltiples empresas, el teletrabajo va a aumentar, el deterioro del poder de negociación de los trabajadores decaerá aún más, la necesidad de un Estado que proteja los empleos y las medidas de rescate se hará necesario. Universidades, colegios, oficinas, librerías, tiendas, hoteles se transformarán o desaparecerán. Trabajar ya no será lo mismo.

\section{Ecología}

Tenemos nuestra tierra sobrecargada, alterada, por un capitalismo destructivo. Millones de traslados de avión diarios, incendios, monocultivos, la pérdida de un quinto de nuestros bosques desde 1960, la contaminación de nuestros océanos. La Gran Aceleración puede acelerar nuestra desaparición. El coronavirus conecta con nuestra crisis ambiental, con la vinculación de los animales con las personas, de los mercados y los laboratorios con lo ecológico. La visión integral de lo ambiental no puede ser una asignatura opcional.

\section{Pararnos}

La globalización supone un movimiento frenético de millones de personas en actividades comerciales, burocráticas y turísticas viviendo en una gran red global.
Todos estamos más cerca unos de otros por la globalización, pero cercanos no quiere decir más solidarios. Lo que está claro es que nos afectamos mutuamente pero no siempre para bien. Tenemos que repensar formas de globalizarnos más solidarias y pararnos un poco. Pero muchos no quieren parar. Hay que seguir produciendo, hay que levantar el PIB. Pero en este tiempo hemos aprendido que no es necesario tener las agendas Ilenas para ser una persona plena. Hay que saber conectarse hondamente con todo lo que ya tenemos. Pero nuestra civilización no sabe parar: siempre dinámicos, productivos, competitivos.

\section{Límites al capitalismo}

E. Macron lo dijo bien claro: "Lo que esta pandemia revela es que existen bienes y servicios que deben quedar fuera de las leyes del mercado". Naomi Klein, de forma tajante, señala: "El coronavirus es el perfecto desastre para el capitalismo del desastre". Esta pandemia ha paralizado el corazón de este sistema especulativo, individualista y antivida. Es necesario aprender lo innecesario de muchas cosas que consumimos. Puede que tengamos que cambiar nuestros modelos de consumo y aprender a disfrutar con menos, con el simple vivir, con el arraigo de la amistad, de los amores, la familia, la conversación y la contemplación. 


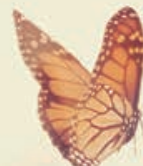

\section{Vulnerabilidad, cuidado,} solidaridad

El coronavirus muestra nuestra vulnerabilidad común. Nadie está libre de romperse por dentro o por fuera. La vulnerabilidad abre nuestras heridas a la necesidad de cuidado mutuo, de cercanía. Lo importante es, como dice Adela Cortina, que los "brotes de solidaridad" que han surgido se consoliden. La meta no puede ser la competición, el deseo de destruir al otro, la envidia. Nuestras sociedades necesitan estructurarse más como sociedades de servicios entre humanos, como sociedades de cuidados.

\section{Conclusión}

Padres y maestros tenemos que integrar la desigualdad creciente, la muerte, la enfermedad, la pérdida, la mujer, la eco-

\section{HEMOS HABLADO DE}

\section{Diálogo; vulnerabilidad; solidaridad; pérdida; memoria; confinamiento; COVID-19.}

Este artículo fue solicitado por PADRES Y MAESTROS en marzo de 2020, revisado y aceptado en mayo de 2020.
Es bueno que los padres se sienten con sus

hijos en un ambiente de tranquilidad a hablar un

rato sobre la pérdida, la larga hospitalización del

abuelo o del amigo, las dificultades del trabajo y

dejar que los sentimientos puedan aflorar y salir

logía, la intimidad, los afectos, la vulnerabilidad, la empatía, las historias, el consumo responsable, el cuidado y el pararse en nuestra manera de "enseñar" este mundo postcoronavirus •

\section{DD. DARA SABER MÂS}

Duro, E. A., et al. (2018). El impacto social de la comunicación en las epidemias: perspectivas bioéticas y de salud pública. Revista Iberoamericana de Bioética, (7), 1-16. https://doi.org/10.14422/rib.i07. y2018.007

Guía para las personas que sufren una pérdida en tiempos del coronavirus. Recuperado de https://bit.ly/3gjPikt

LEE, H. (2014). Matar a un ruiseñor. Barcelona: Ediciones B. 